\title{
Inferring the Genetic Determinants of Fruit Colors in Tomato by Carotenoid Profiling
}

\author{
Hee Ju Yoo ${ }^{1,+}{ }^{\dagger}$, Woo Jung Park ${ }^{2, \dagger}{ }^{\dagger}$ Gyu-Myung Lee ${ }^{1}$, Chang-Sik $\mathrm{Oh}^{3}$, Inhwa Yeam ${ }^{4}$, \\ Dong-Chan Won ${ }^{5}$, Chang Kil Kim ${ }^{1}$ and Je Min Lee ${ }^{1, *}$ \\ 1 Department of Horticultural Science, Kyungpook National University, Daegu 41566, Korea; \\ yhj901003@knu.ac.kr (H.J.Y.); codelkm@naver.com (G.-M.L.); ckkim@knu.ac.kr (C.K.K.) \\ 2 Department of Marine Food Science and Technology, Gangneung-Wonju National University, Gangneung, \\ Gangwon 25457, Korea; pwj0505@gwnu.ac.kr \\ 3 Department of Horticultural Biotechnology, College of Life Science, Kyung Hee University, Yongin, \\ Gyeonggi 17104, Korea; co35@khu.ac.kr \\ 4 Department of Horticulture and Breeding, Andong National University, Andong, Gyeongbuk 36729, Korea; \\ iyeam@andong.ac.kr \\ 5 Breeding Institute, Nongwoo Bio Co., Ltd., Yeoju, Gyeonggi 12655, Korea; dcwon7169@naver.com \\ * Correspondence: jemin@knu.ac.kr; Tel.: +82-53-950-5723 \\ + These authors contributed equally to this work.
}

Academic Editor: Derek J. McPhee

Received: 12 April 2017; Accepted: 2 May 2017; Published: 8 May 2017

\begin{abstract}
Carotenoids are essential for plant and animal nutrition, and are important factors in the variation of pigmentation in fruits, leaves, and flowers. Tomato is a model crop for studying the biology and biotechnology of fleshy fruits, particularly for understanding carotenoid biosynthesis. In commercial tomato cultivars and germplasms, visual phenotyping of the colors of ripe fruits can be done easily. However, subsequent analysis of metabolic profiling is necessary for hypothesizing genetic factors prior to performing time-consuming genetic analysis. We used high performance liquid chromatography (HPLC), employing a $C_{30}$ reverse-phase column, to efficiently resolve nine carotenoids and isomers of several carotenoids in yellow, orange, and red colored ripe tomatoes. High content of lycopene was detected in red tomatoes. The orange tomatoes contained three dominant carotenoids, namely $\delta$-carotene, $\beta$-carotene, and prolycopene. The yellow tomatoes showed low levels of carotenoids compared to red or orange tomatoes. Based on the HPLC profiles, genes responsible for overproducing $\delta$-carotene and prolycopene were described as lycopene $\varepsilon$-cyclase and carotenoid isomerase, respectively. Subsequent genetic analysis using DNA markers for segregating population and germplasms were conducted to confirm the hypothesis. This study establishes the usefulness of metabolic profiling for inferring the genetic determinants of fruit color.
\end{abstract}

Keywords: tomato; carotenoid; fruit color; HPLC; DNA marker; $\delta$-carotene; prolycopene

\section{Introduction}

Tomato (Solanum lycopersicum L.) is a model crop for studying the biology of fleshy fruits, especially carotenoid biosynthesis [1]. In plants, carotenoids protect the cells from excessive radiation and render various colors, such as yellow, orange, and red to flowers, fruits, and vegetative organs [2]. The bright colors of flowers and fruits attract the pollinators and seed dispersers, and thereby, facilitate the propagation of plants. Carotenoids are precursors of plant hormones, such as abscisic acid (ABA) and strigolactones, as well as of various apocarotenoids [3]. Dietary carotenoids are essential for the health of humans as they are unable to synthesize carotenoids de novo [4]. Each carotenoid has its own function in promoting human health. For example, $\beta$-carotene, the precursor of vitamin $\mathrm{A}$, is essential 
for the health of eye and prevents ocular consequences, cataract, and macular degeneration [5]. Similarly, lycopene protects against chronic diseases and decreases the risk of cancer and cardiovascular diseases [6]. Therefore, improving individual carotenoid levels is an important trait in the breeding of many crops.

During ripening, the color of tomato fruit changes from green to red because of increased synthesis of carotenoids, especially lycopene. The carotenoid biosynthesis pathway was identified using genetic and biochemical approaches (Scheme 1) [7-19]. The two precursors of carotenoids, namely, isopentenyl diphosphate (IPP) and dimethylallyl diphosphate (DMAPP), are derived from the methylerythritol 4-phosphate (MEP) pathway. IPP and DMAPP are converted to geranylgeranyl diphosphate (GGPP) by geranylgeranyl diphosphate synthase (GGPPS). Subsequently, the carotenoid biosynthesis pathway is initiated by phytoene synthase (PSY), which condenses two GGPP molecules to form phytoene. Phytoene is desaturated by phytoene desaturase (PDS) to produce phytofluene. PDS, $\zeta$-carotene isomerase (ZISO), and $\zeta$-carotene desaturase (ZDS) catalyze the consecutive steps in the synthesis of cis-lycopene. Carotenoid isomerase (CRTISO) converts cis-lycopene to trans-lycopene by isomerization reactions at 7,9 and $7^{\prime}, 9^{\prime}$ cis-bonds. The trans-lycopene is cyclized through two routes involving lycopene $\varepsilon$-cyclase (LCY-E) and lycopene $\beta$-cyclase (LCY-B). The LCY-E and LCY-B catalyze the synthesis of $\delta$-carotene and $\alpha$-carotene, respectively, through one of the routes that branches at trans-lycopene and leads to the formation of lutein. The other route leads to the synthesis of $\gamma$-carotene and $\beta$-carotene by the catalysis of LCY-B and ultimately results in the formation of neoxanthin.

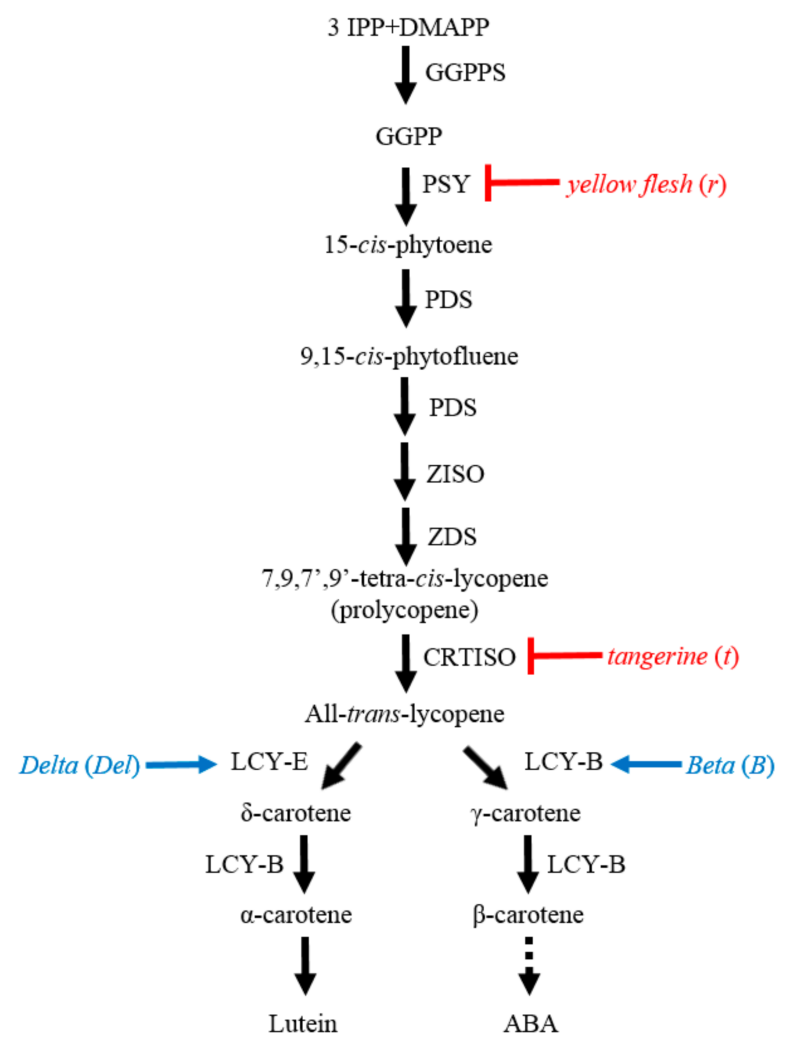

Scheme 1. Carotenoid biosynthetic pathway in tomato. Mutants affecting the carotenoid biosynthesis are represented in italics. Blue color indicates positive regulation and red color indicates negative regulation of carotenogenesis. CRTISO, carotene isomerase; DMAPP, dimethylallyl diphosphate; GGPP, geranylgeranyl diphosphate; GGPPS, geranylgeranyl diphosphate synthase; IPP, isopentenyl diphosphate; LCY-B, lycopene $\beta$-cyclase; LCY-E, lycopene $\varepsilon$-cyclase; PDS, phytoene desaturase;

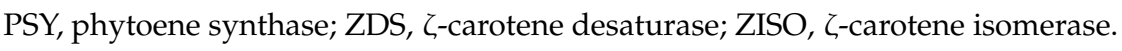

The accumulation of carotenoids is influenced by several factors, such as the intensity of radiation, $\mathrm{CO}_{2}$ concentration, temperature, photo-oxidative stress, and endogenous signals, and the biosynthetic 
genes are spatio-temporally regulated at the transcriptional level [20-31]. Several mutants have been used to study the carotenoid metabolism in tomato [2,17]. The yellow flesh $(r)$ mutant (with loss of PSY1 function) has yellow ripe fruits because of the lack of carotenoid synthesis during ripening [9]. The tangerine $(t)$ mutant (with loss of CRTISO function) rarely produces trans-lycopene [12]. The Delta (Del, overexpressor of $L C Y-E)$ and Beta $(B$, overexpressor of $L C Y-B)$ mutants synthesize high amounts of $\delta$-carotene and $\beta$-carotene, respectively, at the expense of trans-lycopene $[15,16]$. The $t, \mathrm{Del}$, and $B$ mutants show orange ripe fruits because of differences in the carotenoid composition compared to that in the red tomatoes.

The tomato mutants described above were identified by positional cloning and transgenic approaches, which are time-consuming. Several such mutants have been developed [32,33] and germplasms have been collected (for example, see the website of Tomato Genetics Resource Center, http://tgrc.ucdavis.edu/). It is necessary to classify the newly developed resources along with the previously identified resources. The classical phenotyping might not be able to resolve the genetic variations that show similar fruit colors, and time-consuming genetic analysis is impractical. However, prior to the genetic analysis, metabolite analysis can easily and quickly provide information for investigations on the genes involved in carotenoid accumulation in tomato fruits [34]. Direct metabolite analysis approach was developed and used to characterize mutants accumulating high or low amounts of metabolites [35]. Changes in metabolite contents suggest altered enzyme activity and gene expression [36]. Thus, analysis of carotenoid compounds in tomato mutants and germplasms showing different fruit colors can provide important insights into the genes associated with the color. Various methods, such as thin layer chromatography (TLC), liquid chromatography (LC), gas chromatography (GC), mass spectrometry (MS), and nuclear magnetic resonance (NMR), have been used for metabolite analysis [37]. Among these, HPLC combined with UV-Vis detection is especially a well-known method for identification and quantification of carotenoids because of its speed, high resolution, and relatively easy handling [38-40]. Carotenoids are usually separated by reverse-phase HPLC using a $C_{30}$ stationary phase column and are identified by determining the absorption spectrum with a photodiode array detector (PDA) because different carotenoids have unique structures and different absorption maxima $[39,41]$. In this study, we investigated the simultaneous use of metabolite profiling and genetic analysis for identifying the genes regulating the fruit color and carotenoid accumulation in tomato.

\section{Results and Discussion}

\subsection{Separation and Identification of Carotenoid Compounds in Red Tomato Fruits Using HPLC}

To separate and identify the carotenoid compounds in red tomatoes, carotenoids were extracted from the pericarp of S. lycopersicum 'LA3475' (Scheme 2) and then analyzed by HPLC using a $C_{30}$ reverse-phase column and PDA (Figure 1). All the cultivars in this study were of S. lycopersicum and only the cultivar names are used hereafter. The retention time and absorption spectra of the carotenoid compounds in the ripe tomatoes of LA3475 were determined by HPLC and used as reference profiles with which the carotenoid profiles of orange and yellow tomatoes were compared. In a run time of $36 \mathrm{~min}$, carotenoids were detected over a wavelength range from 286 to $471 \mathrm{~nm}$. Seven major carotenoids were identified based on the retention times and absorption spectra identified previously $[39,41]$, with each carotenoid showing a unique absorption spectrum (Table 1 and Figure 1). Phytoene, phytofluene, and lutein were identified based on their absorption at $286 \mathrm{~nm}, 348 \mathrm{~nm}$, and $434 \mathrm{~nm}$, respectively. $\beta$-Carotene and $\gamma$-carotene were identified on the basis of their absorption at $450 \mathrm{~nm}$, and cis- and trans-lycopene were identified on the basis of their absorption at $471 \mathrm{~nm}$. The major component in the red tomato was trans-lycopene, as is already known, and it was detected last at a retention time of $26.4 \mathrm{~min}$. The shape of absorption spectrum, showing the presence of carotenoids, was clear in all the compounds. 
Put $\sim 100$ mg pericarp tissue with 2 glass beads in $2 \mathrm{~mL}$ tube.

Add $300 \mu \mathrm{L}$ of THF containing

$15 \mathrm{mg}$ of Mg-carbonate.

Homogenize the tissue for $45 \mathrm{sec}$ and incubate at $4{ }^{\circ} \mathrm{C}$ (repeat).

Add $300 \mu \mathrm{L}$ of $\mathrm{MeOH} / \mathrm{BHT}$

Homogenize $45 \mathrm{sec}$

and incubate at $4{ }^{\circ} \mathrm{C}$.

Transfer to Spin-X filter. $150 \mu \mathrm{l}$ of THF and $150 \mu \mathrm{L}$ of MeOH/BHT
to original tube and transfer to Spin-X filter.

Separate the extract by

centrifugation for $1 \mathrm{~min}$, $4000 \mathrm{rpm}$ at $4^{\circ} \mathrm{C}$.

Transfer to new $2 \mathrm{~mL}$ tube.

Add $350 \mu \mathrm{L}$ of THF and Incubate for $15 \mathrm{~min}$ at $4{ }^{\circ} \mathrm{C}$.
Analyze carotenoids by HPLC.

Dry the extract for $2 \mathrm{~h}$ at $45^{\circ} \mathrm{C}$

using vacuum centrifuge.

Separate the upper phase and transfer to new $2 \mathrm{~mL}$ tube (repeat).

Separate the extract by centrifugation for $3 \mathrm{~min}$ at $4{ }^{\circ} \mathrm{C}$.

Add $375 \mu \mathrm{L}$ of petroleum ether and $150 \mu \mathrm{L}$ of $25 \% \mathrm{NaCl}$.

Combine filtered extract

in $2 \mathrm{~mL}$ tube.

Separate the extract by centrifugation for $5 \mathrm{~min}$, $4000 \mathrm{rpm}$ at $4^{\circ} \mathrm{C}$.

Add $150 \mu \mathrm{L}$ of THF and incubate $10 \mathrm{~min}$ at $4^{\circ} \mathrm{C}$.

Separate the extract by centrifugation for $5 \mathrm{~min}$, $4000 \mathrm{rpm}$ at $4^{\circ} \mathrm{C}$.

Scheme 2. Procedure for carotenoid extraction from the tomato pericarp. THF, tetrahydrofuran; $\mathrm{MeOH}$, methanol; $\mathrm{BHT}$, butylated hydroxytoluene; $\mathrm{NaCl}$, sodium chloride.

Table 1. Identification of carotenoids in tomato fruits based on the retention time and absorption maxima over the observed wavelength.

\begin{tabular}{cccccccccc}
\hline \multirow{2}{*}{ Compound } & RT (min) & \multicolumn{9}{c}{$\lambda(\mathbf{n m})$} & \multicolumn{3}{c}{ Reported } & Observed Wavelength (nm) \\
\cline { 2 - 8 } & & \multicolumn{3}{c}{ Observed } \\
\hline Phytoene & 16.9 & $(274) *$ & 286 & 298 & $(276)$ & 286 & 297 & 286 \\
\hline Phytofluene & 17.6 & 330 & 350 & 366 & 331 & 348 & 367 & 348 \\
\hline Lutein & 18.4 & 14.3 & $(418)$ & 442 & 470 & $(421)$ & 445 & 474 & 434 \\
$\beta$-carotene & 20.3 & $(422)$ & 450 & 478 & $(425)$ & 449 & 476 & 450 \\
Prolycopene & 20.6 & 414 & 438 & $(466)$ & 414 & 436 & 463 & 450 \\
$\delta$-carotene & 22.3 & 430 & 454 & 486 & 431 & 456 & 489 & 450 \\
$\gamma$-carotene & 23.5 & 438 & 466 & 494 & 437 & 462 & 494 & 450 \\
cis-lycopene & 25.1 & 446 & 470 & 502 & 446 & 472 & 503 & 471 \\
trans-lycopene & 26.4 & 446 & 470 & 502 & 444 & 470 & 502 & 471 \\
\hline
\end{tabular}

* Parentheses indicate the values for the shoulder peaks observed in this study and as reported by Britton et al. [41].

\subsection{Analysis of Carotenoid Profiles in Tomatoes Showing Various Colors of Ripe Fruits}

The carotenoid compounds were extracted from ripe tomato fruits of different colors and were analyzed using HPLC (Figure 2). The composition of carotenoids in the tomato fruits showing yellow and orange colors was clearly different from that in LA3475 tomato with red colored fruits. The major carotenoid peak in LA4099, which has dark orange colored fruits, was detected at $450 \mathrm{~nm}$ at a retention time of $22.3 \mathrm{~min}$; this peak was not detected in LA3475 (Figure 2A). The component detected at $22.3 \mathrm{~min}$ was identified as $\delta$-carotene based on the absorption maxima and spectrum (Table 1). Compared to the peaks in LA3475, a reduced peak of trans-lycopene at a retention time of $26.4 \mathrm{~min}$ and an increased peak area of lutein at a retention time of $14.4 \mathrm{~min}$ were observed. $\delta$-Carotene is synthesized by LCY-E at the expense of trans-lycopene and is a precursor of lutein. Therefore, we assume that the higher accumulation of $\delta$-carotene and lutein was due to the higher expression or activity of $L C Y-E$. 

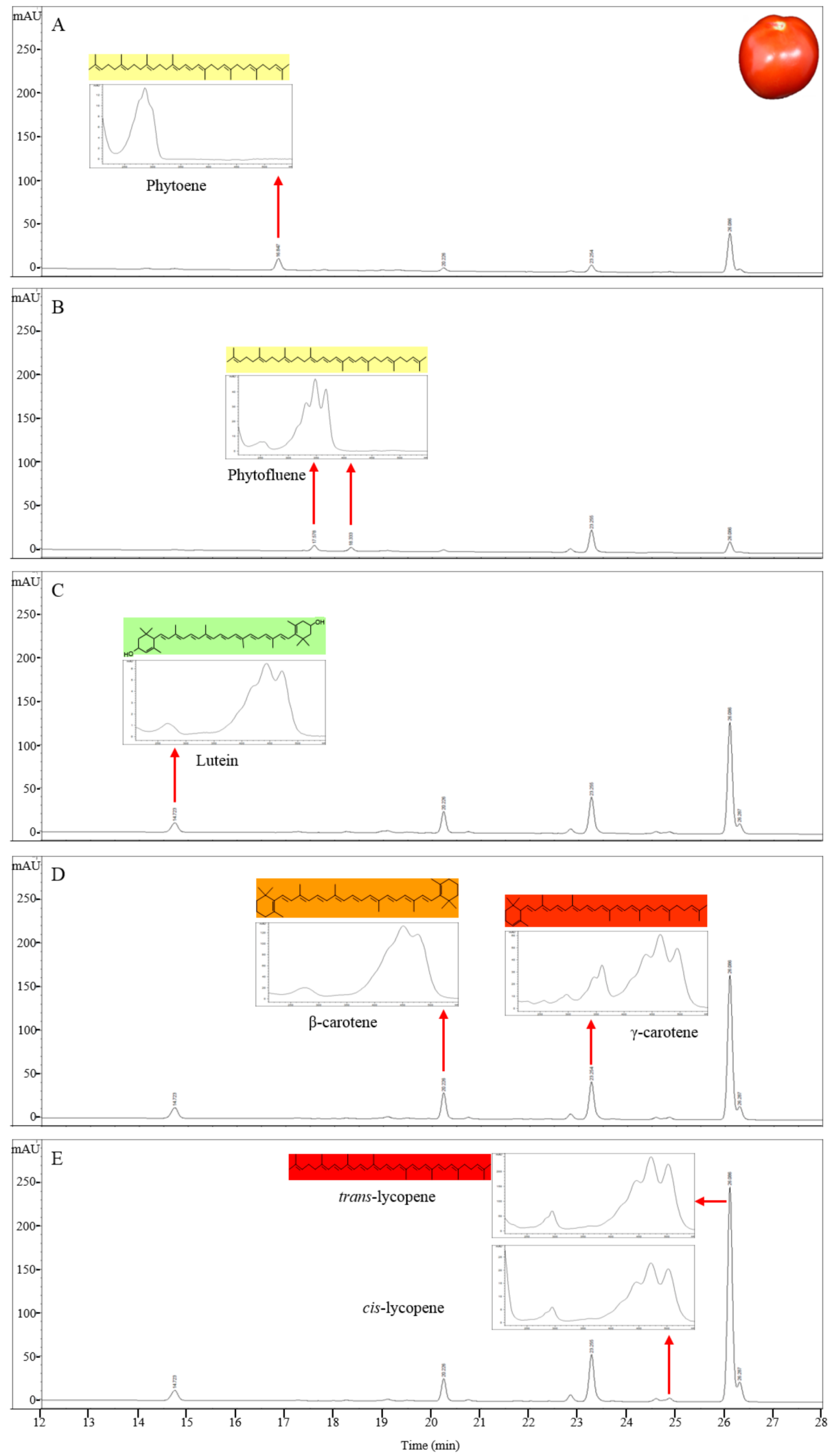

Figure 1. HPLC profile of carotenoids as determined by their absorption between 286 and $471 \mathrm{~nm}$ in red tomato (LA3475). The carotenoid compounds were detected by their absorption at five wavelengths and were identified by their absorption maxima and spectrum. (A) $286 \mathrm{~nm}$; (B) $348 \mathrm{~nm}$; (C) $434 \mathrm{~nm}$; (D) $450 \mathrm{~nm}$; (E) $471 \mathrm{~nm}$ 

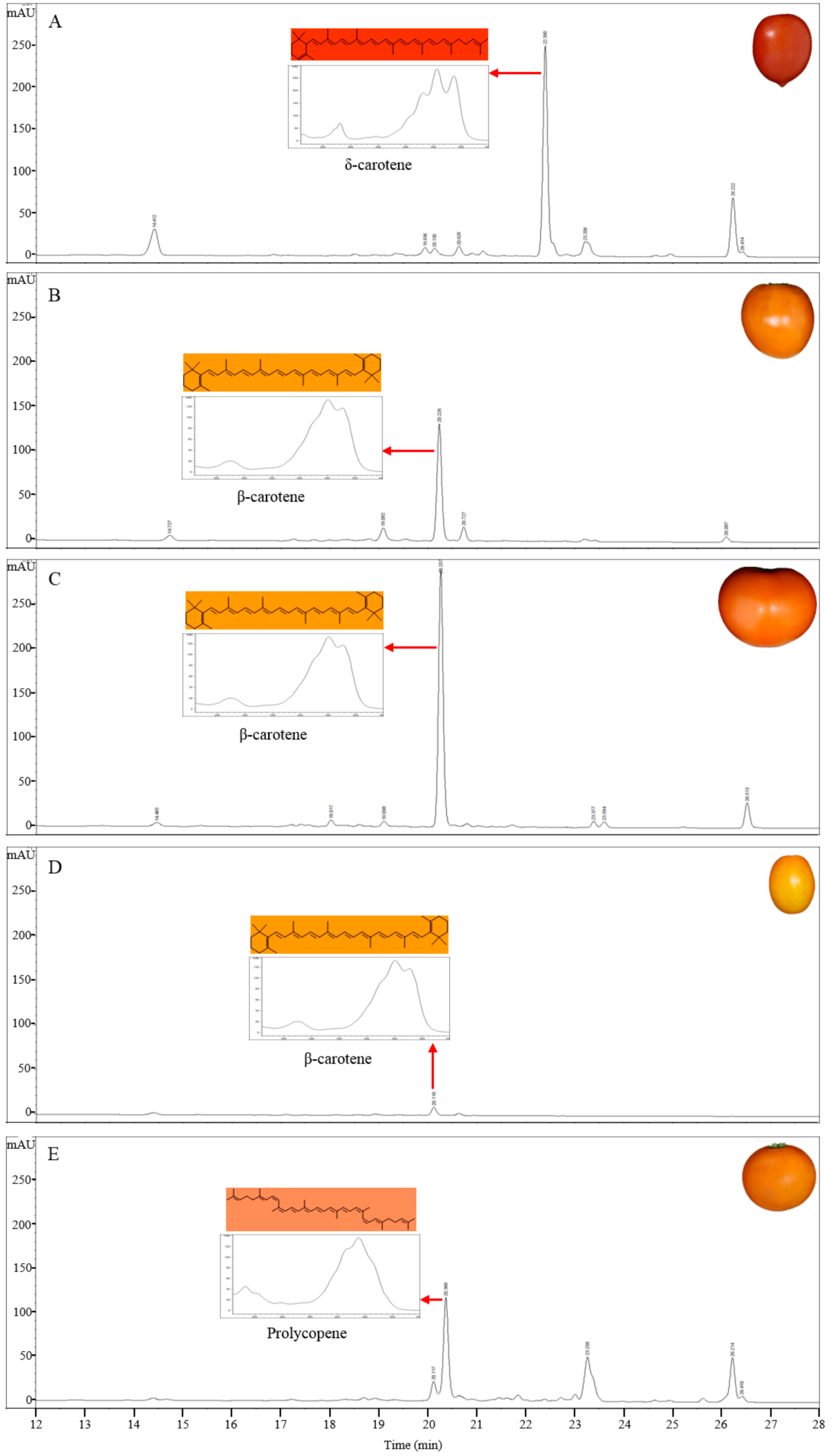

Figure 2. HPLC profiles of carotenoids in tomato germplasms as determined by their absorption at $450 \mathrm{~nm}$. (A) LA4099; (B) LA3311; (C) LA4255; (D) Sugar Yellow; (E) LA3533. Eight other lines (LA0030, LA0351, LA3002, LA3128, LA3183, LA3682, Cispene, and Gold Minichal) accumulating prolycopene showed similar HPLC profiles. 
The orange colored fruits of LA3311 and LA4255 showed higher peak of $\beta$-carotene coupled with reduced peak area of trans-lycopene compared to those in LA3475 (Figure 2B,C). $\beta$-Carotene is synthesized by LCY-B at the expense of lycopene. Therefore, being a $\delta$-carotene over-producing line, high expression or activity of LCY-B is a major determinant in the high accumulation of $\beta$-carotene.

The HPLC profile in Sugar Yellow tomato with yellow-colored fruits was different from that of the other tomato lines. The $\beta$-carotene content was much lower than that of other lines and the level of other carotenoids were also very low. Furthermore, lycopene was not detected (Figure 2D). These results indicate that Sugar Yellow is mutated in a gene upstream of carotenoid or isoprenoid biosynthesis such as yellow flesh ( $r$ ) [11] or apricot (at) [42], showing lack of carotenoids in ripe tomato fruits. In the at mutant, the flower color showed deficiency of carotenoids unlike in the $r$ mutant. The flower color in Sugar Yellow was same as that in the wild type (data not shown) suggesting that the at mutation may not affect the fruit color variation in Sugar Yellow. The ripening mutants normally showed lack of carotenoid in addition to the ripening phenotypes, such as higher fruit firmness. Sugar Yellow showed normal ripening patterns as in the wild type.

LA0030, LA3183, LA3533, LA3682, Gold Minichal, and Cispene with orange ripe fruit color contain lower amounts of $\beta$-carotene and lycopene compared to that in LA3475. HPLC analysis of these lines showed major absorption peaks at $450 \mathrm{~nm}$ at a retention time of $20.6 \mathrm{~min}$, which were identified to be prolycopene based on the absorption maxima and spectrum (Figure 2E). Prolycopene $\left(7,9,7^{\prime}, 9^{\prime}\right.$-tetra-cis-lycopene), showed different absorption spectrum and retention time compared to cis-lycopene detected in red tomato. Thus, prolycopene is a representative carotenoid only present in these lines. Subsequently, these lines were assumed to be regulated by the mutation in CRTISO [13], which is responsible for cis- to trans-lycopene isomerization. Therefore, interrupting the synthesis of trans-lycopene may lead to the accumulation of its precursor, prolycopene, and the appearance of orange color.

\subsection{Association Analysis between HPLC Profiles and Genotype Screening for Carotenoid Accumulation}

The dark orange colored fruit in LA4099 contained a high amount of $\delta$-carotene and a low amount of trans-lycopene compared to the amounts of these present in the red tomato fruit of LA3475 (Figure 2A). Based on the carotenoid profile and subsequent hypothesis-driven approach, LCY-E might be supposed to be mutated or up-regulated in LA4099. The changes in gene expression are often due to genetic variations in the promoter regions. Thus, promoter regions of LCY-E in LA4099 and LA3475 were sequenced and compared to identify the genetic variation. In LA4099, 1,014 bp nucleotides were inserted in the promoter region at $-326 \mathrm{bp}$ position from the start codon (Figure $3 \mathrm{~A}$ ). To identify this variation in LA4099, INDEL marker (LCY-e1) of LCY-E was developed (Table 2). To verify whether the fruit colors were genetically determined by the variation in $L C Y-E$, LA3475 and LA4099 were crossed, and genetic and phenotypic analyses were conducted in their $\mathrm{F}_{2}$ population (Figure $3 \mathrm{~B}$ ). The $\mathrm{F}_{1}$ fruits of LA3475 $\times$ LA4099 showed orange color as in LA4099, and the $F_{2}$ progenies segregated into those with orange (66 individuals) and red (28 individuals) colored ripe fruits at a ratio of $3: 1\left(\chi^{2}=1.15\right.$, $p$-value $=0.2838)$. The genotypes of $L C Y-E$ in the $F_{2}$ population were analyzed using the INDEL marker. We could identify 19 homozygous individuals of the LA4099 type (orange fruits), 47 heterozygous individuals (orange fruits), 28 homozygous individuals of the LA3475 type (red fruits), as per the expected genotypic ratio of 1:2:1 $\left(\chi^{2}=1.72, p\right.$-value $\left.=0.4244\right)$. The genotypic data co-segregated with the phenotypic data, suggesting that $L C Y-E$ is the genetic determinant of the dark orange fruit color in the $\delta$-carotene overproducer, LA4099.

The $\delta$-carotene over accumulating tomato, with high activity of $L C Y$-E, is a candidate source for increased lutein. In a previous study, transgenic tomato over-expressing LCY-E showed higher accumulation of $\delta$-carotene. This transgenic line was crossed with the Beta mutant (overexpressing $L C Y-B)$ and the resulting hybrid line was shown to accumulate high amounts of lutein because of the over-expression of $L C Y-E$ and $L C Y-B$ [43]. Lutein, a macular pigment in addition to zeaxanthin, is a functional nutrient. In addition, lutein plays a role in the protection of eye by absorbing the blue 
light, which causes light-induced injury in the photoreceptor cells [44]. Therefore, $\delta$-carotene-enriched line can be a useful source for improving the lutein content in tomato fruit.

A

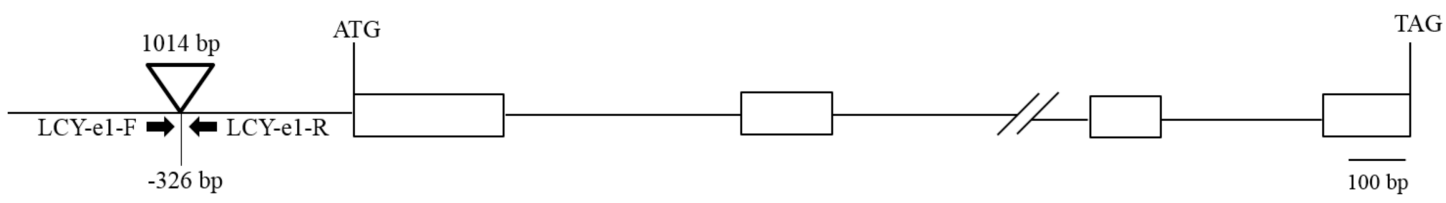

B

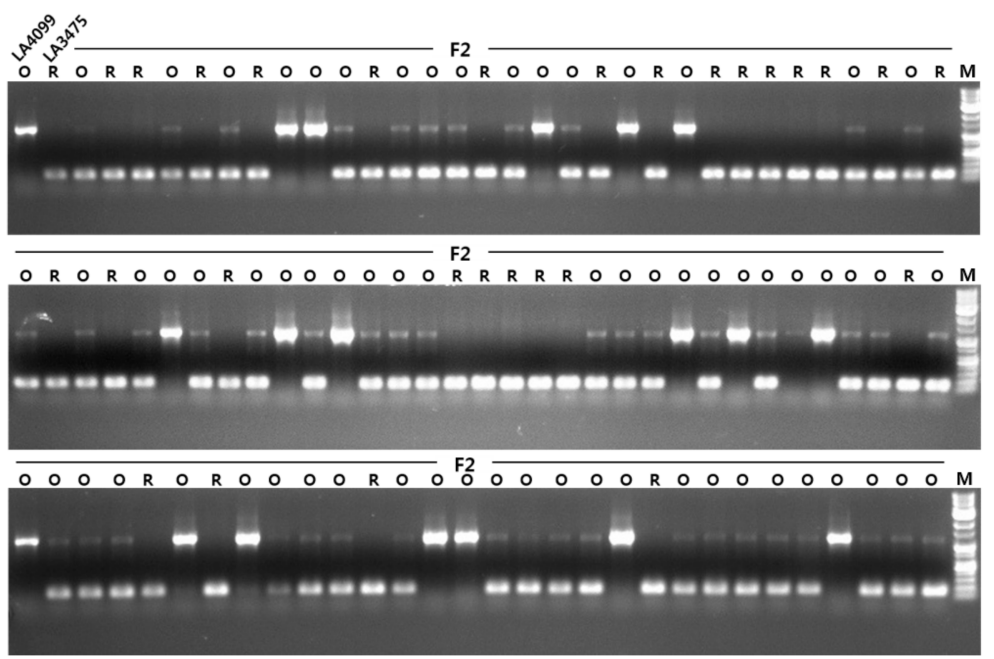

Figure 3. The variation in fruit color in LA4099 co-segregated with $L C Y-E$ in $\mathrm{F}_{2}$ population derived from a cross between LA3475 and LA4099. (A) Gene structure of $L C Y-E$ and its genetic variation in LA4099. A DNA fragment of $1014 \mathrm{bp}$ was inserted at the promoter region of LCY-E in LA4099; (B) Co-segregation analysis between $L C Y-E$ and the dark orange fruit colors in $\mathrm{F}_{2}$ population of LA3475 $\times$ LA4099. The insertion at $L C Y-E$ was distinguished by a DNA marker (LCY-e1). The marker co-segregated with the fruit colors in $94 \mathrm{~F}_{2}$ progenies derived from a cross of LA3475 and LA4099. $\mathrm{O}$ and $\mathrm{R}$ represent the orange and red fruit colors, respectively, in the parental lines and $\mathrm{F}_{2}$ population. $\mathrm{M}$ indicates $1 \mathrm{~kb}$ DNA ladder.

Table 2. Primers of $L C Y-E$ and CRTISO used for sequence analysis and genotyping.

\begin{tabular}{cccc}
\hline Marker Name & Primer Name & Sequence $\left(\mathbf{5}^{\prime}-\mathbf{3}^{\prime}\right)$ & $\mathbf{T}_{\mathbf{m}}\left({ }^{\circ} \mathbf{C}\right)$ \\
\hline \multirow{2}{*}{ LCY-e1 } & LCY-e1-F & CATGTTTGAAAACAAGCCAATATTG & 56.4 \\
& LCY-e1-R & TGCTGGAGTTATTTCATCTTGAC & 57.0 \\
\hline \multirow{2}{*}{ CRTISO } & CRTISO-F & AGTCGAATCAATCTGAATTCACCT & 57.5 \\
& CRTISO-R & GGTCAAAACAAGAACTTCTCTGTT & 57.5 \\
\hline \multirow{3}{*}{ Primers for CRTISO cloning } & CRTISO-gDNA-1F & TCTTGGGTTTCCAGCAATTTAAAG & 57.5 \\
& CRTISO-gDNA-1R & AACTTCTAATTTACGTCCTACTGC & 57.5 \\
& CRTISO-gDNA-2F & TACTATTGTATATGGTCTGCAGTG & 57.5 \\
& CRTISO-gDNA-2R & AGAATTACCATGCTTGCATTGATC & 57.5 \\
& CRTISO-gDNA-3F & TTGCTGTCTTTTATAGATGCAGAG & 57.5 \\
& CRTISO-gDNA-4F & TCAGTTACATCCCTGAAGTTATTC & 57.5 \\
& CRTISO-gDNA-4R & GTAAACATAGATGGTGTAACTCCA & 57.5 \\
& CRTISO-gDNA-5F & CTGAAAGGATTATAAGCAGACTTG & 57.5 \\
& CRTISO-gDNA-5R & AATCTGTGATTTCTATACTGGAGG & 57.5 \\
\hline
\end{tabular}

Nine tomato lines (LA0030, LA0351, LA3002, LA3128, LA3183, LA3533, LA3682, Cispene, and Gold Minichal) showing orange fruit color accumulated increased amounts of prolycopene 
and reduced amounts of trans-lycopene compared to LA3475 (Figure 2E). Because the candidate gene affecting this variation was inferred to be CRTISO, the variations in CRTISO in these lines were investigated. In a previous study, the CRTISO mutant, tangerine, was found to be enriched with prolycopene and had deletions of $282 \mathrm{bp}$ and $348 \mathrm{bp}$ in the 1st exon and 1st intron and promoter regions, respectively [12]. Among the two reported variations, the deletion of $348 \mathrm{bp}$ at the promoter region was discovered in six lines (LA0030, LA3183, LA3533, LA3682, Cispene, and Gold Minichal) by the INDEL marker of CRTISO whereas three lines (LA0351, LA3002, and LA3128) did not contain the deletion (Figure 4, Table 2). Thus, the genomic DNAs of CRTISO in these lines were sequenced using five primers (Table 2) and compared with that of the wild type, LA3475. Nonsense mutations caused by the insertion of thymine in the 2nd exon (LA3002) and adenine in the 8th exon (LA3128) were discovered. A missense mutation was found to convert cytosine to thymine in the 7 th exon in LA0351. In addition to the previously identified tangerine allele, these three alleles would be valuable for improving the prolycopene content in tomato breeding.

A

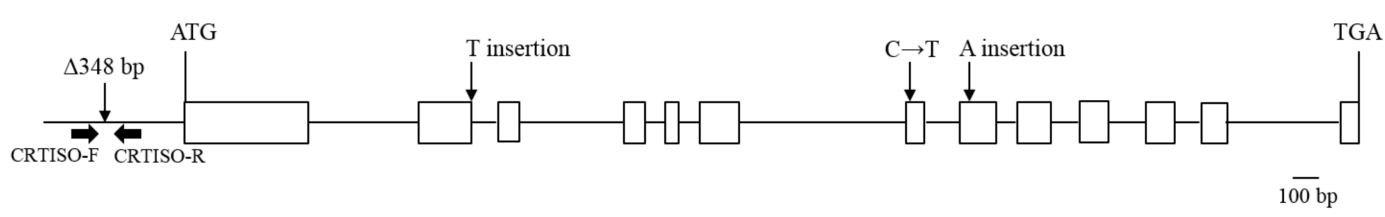

B

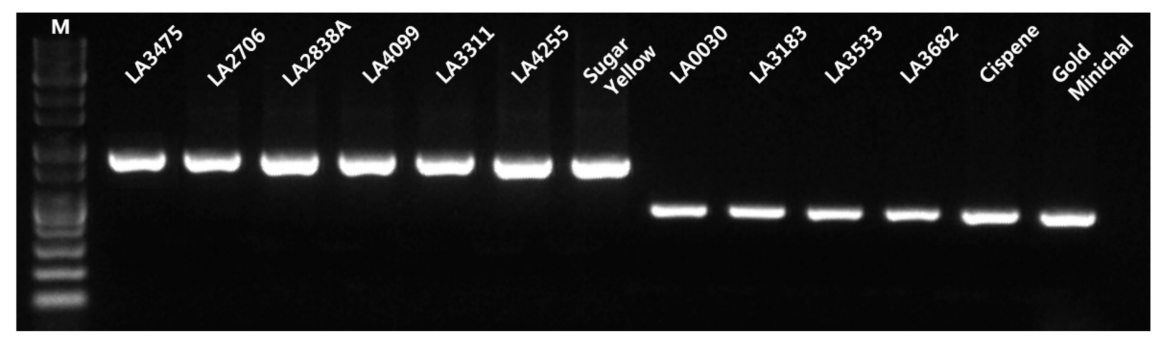

Figure 4. Gene structure of CRTISO and genotypic analysis of orange tomatoes enriched in prolycopene using the INDEL maker of CRTISO. (A) CRTISO mutation at the promoter region was previously identified [12] and three new mutations were identified in the coding region in this study. Two nonsense mutations were caused by one nucleotide insertion in the 2nd and 8th exons, respectively, and a missense mutation ( $\mathrm{C}$ to $\mathrm{T}$ ) was found in the 7th exon; (B) Deletion at the promoter region of CRTISO was distinguished by DNA marker (CRTISO) in prolycopene over-accumulated lines. Other tomatoes showing various colors, such as red (LA3475, LA2706, LA2838A), orange (LA4099, LA3311, LA4255), and yellow (Sugar Yellow) showed no deletion at the promoter region of CRTISO. M indicates $1 \mathrm{~kb}$ DNA ladder.

Prolycopene is one of the cis-lycopene isomers mainly present in the human blood and tissues although trans-lycopene is the principal form of lycopene in red tomato [45]. Humans efficiently absorb more cis-lycopene isomer from the $t$ mutant tomato sauce compared to equal amounts of trans-lycopene from red tomato sauce in their total serum [46]. Thus, CRTISO mutants would be useful resources for improving the bioavailability of lycopene [47].

The red color of tomato is because of the higher accumulation of trans-lycopene, whereas carotenes and xanthophylls impart orange and yellow colors, respectively. Thus, it is difficult to distinguish the genetic variation visually because most of the tomato mutants with defect in the carotenoid biosynthesis genes show orange and yellow colored ripe fruits. In this study, we identified distinct carotenoid profiles of tomatoes showing diverse fruit colors and inferred the candidate genes for each variation in addition to the genetic analysis. Visual phenotypes were often connected with dramatic metabolic changes. Thus, metabolic profiling can be a highly efficient method to infer the 
genetic determinants regulating the metabolite synthesis or accumulation before conducting the time-consuming genetic analysis.

\section{Materials and Methods}

\subsection{Plant Materials}

Thirteen tomato germplasms and three commercial cultivars (three red tomatoes, twelve orange tomatoes, and one yellow tomato) were used for the profiling of carotenoids. The tomato plants were grown in a greenhouse with $16 \mathrm{~h}$ light $/ 8 \mathrm{~h}$ dark period at temperatures ranging from 19 to $28^{\circ} \mathrm{C}$, $50-70 \%$ relative humidity. After fruit setting, $2 \mathrm{~g}$ of water soluble NPK fertilizer $(17-8-26+2 \mathrm{MgO}$ with micro nutrient, Poly-Feed ${ }^{\mathrm{TM}}$ Drip, Haifa Chemicals Ltd., Matam-Haifa, Israel) per each plant were supplied every week. Three ripe fruits (ten days post-breaker stage) per each line were harvested for evaluation of fruit colors and extraction of carotenoids from the pericarp. The fruit colors were evaluated by three persons. The harvested pericarps were immediately frozen in liquid nitrogen and stored at $-80^{\circ} \mathrm{C}$ before the extraction of carotenoids.

\subsection{Carotenoid Extraction}

To prevent the degradation and oxidation of carotenoids, all the experiments were conducted under limited light conditions. For carotenoid extraction, the method of extraction described by Vrebalov et al. [25] was used with some modifications and a schematic diagram for the same is presented in Scheme 2. All the solvents used were of HPLC grade. Frozen tomatoes were ground and about $100 \mathrm{mg}$ of the tissue powder was placed in a $2 \mathrm{~mL}$ tube with two glass beads $(6 \mathrm{~mm})$. The frozen tissues were homogenized with $15 \mathrm{mg}$ of magnesium carbonate and $300 \mu \mathrm{L}$ of tetrahydrofuran (THF) for $60 \mathrm{~s}$ using FastPrep-24 ${ }^{\mathrm{TM}}$ instrument (MP Biomedicals, Santa Ana, CA, USA). The extracts were homogenized again after adding $300 \mu \mathrm{L}$ of methanol $(\mathrm{MeOH})$ containing $5 \%$ butylated hydroxyl-toluene (BHT). The homogenate was transferred to Spin- $X$ centrifuge filter tube $(0.45-\mathrm{mm}$ nylon filter, Corning Incorporated, Corning, NY, USA) and centrifuged for $1 \mathrm{~min}$ at $4000 \mathrm{rpm}$ at $4{ }^{\circ} \mathrm{C}$. The original $2 \mathrm{~mL}$ tube was kept on ice and $150 \mu \mathrm{L}$ of THF and $150 \mu \mathrm{L}$ of $\mathrm{MeOH}$, containing $5 \%$ BHT, were added to the tube. The tissue debris in the original tube was transferred using a cut tip to Spin-X centrifuge filter tube and then centrifuged for $1 \mathrm{~min}$ at $4000 \mathrm{rpm}$ and $4{ }^{\circ} \mathrm{C}$. The filtered extract was transferred to a new $2 \mathrm{~mL}$ tube. For the complete extraction of carotenoid, $350 \mu \mathrm{L}$ of THF was added in Spin-X centrifuge filter tube, incubated on ice for $15 \mathrm{~min}$, and then centrifuged at $4000 \mathrm{rpm}$ for $5 \mathrm{~min}$ at $4{ }^{\circ} \mathrm{C}$. This step was repeated. The filtered extract was combined with the previous extract in a $2 \mathrm{~mL}$ tube. To separate the carotenoid/nonpolar phase from the aqueous phase, $375 \mu \mathrm{L}$ of petroleum ether and $150 \mu \mathrm{L}$ of $25 \%$ sodium chloride were added into the filtered extract, vortexed vigorously, and centrifuged for $3 \mathrm{~min}$. The upper phase was separated from the lower phase or inter-phase into a new $2 \mathrm{~mL}$ tube. For re-extraction, $500 \mu \mathrm{L}$ of petroleum ether was added and the upper phase was separated as described for the previous step. The petroleum ether extract was dried using MICRO-CENVAC machine (NB-503CIR, N-BIOTEK, Bucheon, Korea) for $2 \mathrm{~h}$ at $45^{\circ} \mathrm{C}$. If HPLC was not performed immediately, the carotenoid extract was stored at $-80^{\circ} \mathrm{C}$.

\subsection{Carotenoid Analysis Using HPLC}

The carotenoid extracts were suspended in $250 \mu \mathrm{L}$ of methyl $t$-butyl ether and $242 \mu \mathrm{L}$ of $\mathrm{MeOH}$. The carotenoid suspension was filtered through a $0.45-\mu \mathrm{m}$ syringe filter $\left(\right.$ SmartPor $^{\circledR}-\mathrm{II}$ NYLON Syringe filter with $13 \mathrm{~mm}, 0.45 \mu \mathrm{m}$, Woongki Science Co., Ltd., Seoul, Korea) and put in an HPLC vial. The carotenoid analysis was performed using a 1260 Infinity series HPLC instrument (Agilent, Santa Clara, CA, USA) and the Chemstation software. The injection volume was $25 \mu \mathrm{L}$ and the flow rate was $1 \mathrm{~mL} \mathrm{~min}^{-1}$. The column temperature was maintained at $25^{\circ} \mathrm{C}$ for all the analyses. The carotenoids were separated under a polar to nonpolar gradient using mobile phases consisting of $100 \%$ methanol with $0.1 \%$ ammonium acetate (A) and methyl t-butyl ether (B) through a guard column 
(YMC Guard Cartridge, YMC Co., Ltd., Kyoto, Japan) and $C_{30}$ stationary phase (YMC Carotenoid S-5 $\mu \mathrm{m}, 250 \times 4.6 \mathrm{~mm}$, YMC Co., Ltd., Kyoto, Japan). A gradient elution was performed with $100 \%$ of A for $6 \mathrm{~min}$, which was then gradated to $4 \%$ of A and $96 \%$ of B over $20 \mathrm{~min}$. After 26 min, A was increased to $100 \%$ until $36 \mathrm{~min}$. The elution of carotenoids was observed on an online Diode Array Detector (PDA) at five wavelengths $(286 \mathrm{~nm}, 348 \mathrm{~nm}, 434 \mathrm{~nm}, 450 \mathrm{~nm}$, and $471 \mathrm{~nm})$. The carotenoids were identified based on their absorption maxima and spectrum $[39,41]$.

\subsection{DNA Extraction}

The genomic DNA of tomato was extracted using a modified cetyltrimethylammonium bromide (CTAB) method [48]. The young leaf tissue was homogenized in FastPrep-24 ${ }^{\mathrm{TM}}$ instrument (MP Biomedicals, Santa Ana, CA, USA) with two glass beads $(6 \mathrm{~mm}), 600 \mu \mathrm{L}$ of CTAB buffer (2\% CTAB, $1.42 \mathrm{M} \mathrm{NaCl}, 20 \mathrm{mM}$ ethylenediaminetetraacetic acid (EDTA), $100 \mathrm{mM}$ Tris-Cl (pH 8.0)), $0.5 \% \beta$-mercaptoethanol, and $1 \mathrm{mg}$ of L-ascorbic acid in a $2 \mathrm{~mL}$ tube. The extract was incubated at $65{ }^{\circ} \mathrm{C}$ for $15 \mathrm{~min}$. Thereafter, $600 \mu \mathrm{L}$ of chloroform:isoamyl alcohol $(24: 1 v / v)$ was added and mixed well. The extract was centrifuged at $13,000 \mathrm{rpm}$ for $15 \mathrm{~min}$ at $4{ }^{\circ} \mathrm{C}$. The upper phase was transferred to a new tube and $500 \mu \mathrm{L}$ of isopropanol was added and then the mixture was centrifuged at 13,000 rpm for $15 \mathrm{~min}$ at $4{ }^{\circ} \mathrm{C}$. The supernatant was removed and $70 \%$ ethanol was added to the pellet and then centrifuged at 13,000 rpm for $5 \mathrm{~min}$ at $4{ }^{\circ} \mathrm{C}$. Ethanol was removed and the extract was centrifuged for $1 \mathrm{~min}$. The remaining ethanol was removed and $30 \mu \mathrm{L}$ of $\mathrm{ddH}_{2} \mathrm{O}$ containing $1 \%$ RNase was added to the pellet.

\subsection{Sequence Analysis and DNA Marker Analysis}

Polymerase chain reaction (PCR) was conducted using e-Taq DNA polymerase (SolGent, Daejeon, Korea) in a T-100 Thermal Cycler (BIO-RAD, Hercules, CA, USA), with $100 \mathrm{ng}$ of each DNA template and 10 pmol of gene specific primers for LCY-E (Solyc12g008980) and CRTISO (Solyc10g081650) (Table 2). The PCR conditions were $95{ }^{\circ} \mathrm{C}$ for $3 \mathrm{~min}$, followed by 35 cycles of $95^{\circ} \mathrm{C}$ for $1 \mathrm{~min}, 56^{\circ} \mathrm{C}$ for $1 \mathrm{~min}$, and $72{ }^{\circ} \mathrm{C}$ for $2 \mathrm{~min}$. The amplified fragments were cloned into T-blunt vector (T-Blunt ${ }^{\mathrm{TM}}$ PCR Cloning Kit, SolGent, Daejeon, Korea), as per the manufacturer's protocol, and transformed into E. coli $(\mathrm{DH} 5 \alpha)$. The plasmid DNA was isolated by a plasmid prep kit (HiGene ${ }^{\mathrm{TM}}$ Plasmid Mini Prep Kit, BIOFACT, Daejeon, Korea). The sequence analysis was performed at SolGent. The LCY-e1 and CRTISO primers were used as DNA markers for screening the genotype of LCY-E and CRTISO, respectively. The PCR products obtained using the DNA markers were separated by electrophoresis on $1 \%$ agarose gel and were visualized by staining with ethidium bromide.

\section{Conclusions}

Tomato fruits show various colors, such as red, pink, orange, yellow, brown, and purple. Among the diverse pigments affecting the fruit color, carotenoids are the primary determinants. Therefore, diverse color mutants often affect the carotenoid synthesis. Identification of genetic factors affecting the variation in fruit colors is time-consuming and labor intensive. Visual phenotypes underlying different genotypes are often indistinguishable from each other. Our study could distinguish similar fruit color variation by carotenoid profiling. Four distinct carotenoid profiles were investigated, and two candidate genes affecting fruit color and carotenoid variation were verified. Metabolite analysis using HPLC is an efficient tool for identifying the genes regulating the carotenoid biosynthesis in tomato. Metabolomics analysis in the field of genetics and breeding should be conducted for hypothesizing the mode of genetic action.

Acknowledgments: This research was supported by the National Research Foundation of Korea (No. 2014R1A1A1038130). This research was also supported by the Vegetable Breeding Research Center and the Golden Seed Project (Center for Horticultural Seed Development) funded by the Ministry of Agriculture, Food and Rural Affairs of Korea. 
Author Contributions: J.M.L. and H.J.Y. conceived and designed the experiments; H.J.Y. and G.-M.L. performed the experiments; H.J.Y. and J.M.L. analyzed the data; W.J.P., C.-S.O., I.Y., D.-C.W., C.K.K. and J.M.L. contributed reagents, materials and analysis tools; H.J.Y., W.J.P. and J.M.L. wrote the paper.

Conflicts of Interest: The authors declare no conflict of interest.

\section{References}

1. The Tomato Genome Consortium. The tomato genome sequence provides insights into fleshy fruit evolution. Nature 2012, 485, 635-641. [CrossRef]

2. Giuliano, G.; Bartley, G.E.; Scolnik, P.A. Regulation of carotenoid biosynthesis during tomato development. Plant Cell 1993, 5, 379-387. [CrossRef] [PubMed]

3. Ahrazem, O.; Gómez-Gómez, L.; Rodrigo, M.; Avalos, J.; Limón, M. Carotenoid Cleavage Oxygenases from Microbes and Photosynthetic Organisms: Features and Functions. Int. J. Mol. Sci. 2016, 17, e1781. [CrossRef] [PubMed]

4. Nisar, N.; Li, L.; Lu, S.; Khin, N.C.; Pogson, B.J. Carotenoid metabolism in plants. Mol. Plant 2015, 8, 68-82. [CrossRef] [PubMed]

5. Fraser, P.D.; Bramley, P.M. The biosynthesis and nutritional uses of carotenoids. Prog. Lipid Res. 2004, 43, 228-265. [CrossRef] [PubMed]

6. Ford, N.A.; Erdman, J.W. Are lycopene metabolites metabolically active. Acta Biochim. Pol. 2012, 59, 1-4. [PubMed]

7. Cookson, P.J.; Kiano, J.W.; Shipton, C.A.; Fraser, P.D.; Romer, S.; Schuch, W.; Bramley, P.M.; Pyke, K.A. Increases in cell elongation, plastid compartment size and phytoene synthase activity underlie the phenotype of the high pigment-1 mutant of tomato. Planta 2003, 217, 896-903. [CrossRef] [PubMed]

8. Fantini, E.; Falcone, G.; Frusciante, S.; Giliberto, L.; Giuliano, G. Dissection of tomato lycopene biosynthesis through virus-induced gene silencing. Plant Physiol. 2013, 163, 986-998. [CrossRef] [PubMed]

9. Fraser, P.D.; Enfissi, E.M.; Halket, J.M.; Truesdale, M.R.; Yu, D.; Gerrish, C.; Bramley, P.M. Manipulation of phytoene levels in tomato fruit: Effects on isoprenoids, plastids, and intermediary metabolism. Plant Cell 2007, 19, 3194-3211. [CrossRef] [PubMed]

10. Fraser, P.D.; Romer, S.; Shipton, C.A.; Mills, P.B.; Kiano, J.W.; Misawa, N.; Drake, R.G.; Schuch, W.; Bramley, P.M. Evaluation of transgenic tomato plants expressing an additional phytoene synthase in a fruit-specific manner. Proc. Natl. Acad. Sci. USA 2002, 99, 1092-1097. [CrossRef] [PubMed]

11. Fray, R.G.; Grierson, D. Identification and genetic analysis of normal and mutant phytoene synthase genes of tomato by sequencing, complementation and co-suppression. Plant Mol. Biol. 1993, 22, 589-602. [CrossRef] [PubMed]

12. Isaacson, T.; Ronen, G.; Zamir, D.; Hirschberg, J. Cloning of tangerine from Tomato Reveals a Carotenoid Isomerase Essential for the Production of $\beta$-Carotene and Xanthophylls in Plants. Plant Cell 2002, 14, 333-342. [CrossRef] [PubMed]

13. Isaacson, T.; Ohad, I.; Beyer, P.; Hirschberg, J. Analysis in Vitro of the Enzyme CRTISO Establishes a Poly-cis-Carotenoid Biosynthesis Pathway in Plants. Plant Physiol. 2004, 136, 4246-4255. [CrossRef]

14. Luo, Z.; Zhang, J.; Li, J.; Yang, C.; Wang, T.; Ouyang, B.; Li, H.; Giovannoni, J.; Ye, Z. A STAY-GREEN protein SISGR1 regulates lycopene and beta-carotene accumulation by interacting directly with SIPSY1 during ripening processes in tomato. New Phytol. 2013, 198, 442-452. [CrossRef] [PubMed]

15. Ronen, G.; Carmel-Goren, L.; Zamir, D.; Hirschberg, J. An alternative pathway to $\beta$-carotene formation in plant chromoplasts discovered by map-based cloning of beta and old-gold color mutations in tomato. Proc. Natl. Acad. Sci. USA 2000, 97, 11102-11107. [CrossRef] [PubMed]

16. Ronen, G.; Cohen, M.; Zamir, D.; Hirschberg, Z. Regulation of carotenoid biosynthesis during tomato fruit development: Expression of the gene for lycopene epsilon-cyclase is down-regulated during ripening and is elevated in the mutant Delta. Plant J. 1999, 17, 341-351. [CrossRef] [PubMed]

17. Liu, L.; Shao, Z.; Zhang, M.; Wang, Q. Regulation of carotenoid metabolism in tomato. Mol. Plant 2015, 8, 28-39. [CrossRef] [PubMed]

18. Rosati, C.; Aquilani, R.; Dharmapuri, S.; Pallara, P.; Marusic, C.; Tavazza, R.; Bouvier, F.; Camara, B.; Giuliano, G. Metabolic engineering of beta-carotene and lycopene content in tomato fruit. Plant J. 2000, 24, 413-420. [CrossRef] [PubMed] 
19. Kachanovsky, D.E.; Filler, S.; Isaacson, T.; Hirschberg, J. Epistasis in tomato color mutations involves regulation of phytoene synthase 1 expression by cis-carotenoids. Proc. Natl. Acad. Sci. USA 2012, 109, 19021-19026. [CrossRef] [PubMed]

20. Alba, R.; Cordonnier-Pratt, M.M.; Pratt, L.H. Fruit-Localized Phytochromes Regulate Lycopene Accumulation Independently of Ethylene Production in Tomato. Plant Physiol. 2000, 123, 363-370. [CrossRef] [PubMed]

21. Schofield, A.; Paliyath, G. Modulation of carotenoid biosynthesis during tomato fruit ripening through phytochrome regulation of phytoene synthase activity. Plant Physiol. Biochem. 2005, 43, 1052-1060. [CrossRef] [PubMed]

22. Cocaliadis, M.F.; Fernández-Muñoz, R.; Pons, C.; Orzaez, D.; Granell, A. Increasing tomato fruit quality by enhancing fruit chloroplast function. A double-edged sword? J. Exp. Bot. 2014, 65, 4589-4598. [CrossRef] [PubMed]

23. Dumas, Y.; Dadomo, M.; Di Lucca, G.; Grolier, P. Effects of environmental factors and agricultural techniques on antioxidantcontent of tomatoes. J. Sci. Food Agric. 2003, 83, 369-382. [CrossRef]

24. Martel, C.; Vrebalov, J.; Tafelmeyer, P.; Giovannoni, J.J. The tomato MADS-box transcription factor RIPENING INHIBITOR interacts with promoters involved in numerous ripening processes in a COLORLESS NONRIPENING-dependent manner. Plant Physiol. 2011, 157, 1568-1579. [CrossRef] [PubMed]

25. Vrebalov, J.; Pan, I.L.; Arroyo, A.J.; McQuinn, R.; Chung, M.; Poole, M.; Rose, J.; Seymour, G.; Grandillo, S.; Giovannoni, J.; et al. Fleshy fruit expansion and ripening are regulated by the Tomato SHATTERPROOF gene TAGL1. Plant Cell 2009, 21, 3041-3062. [CrossRef] [PubMed]

26. Liu, Y.; Roof, S.; Ye, Z.; Barry, C.; van Tuinen, A.; Vrebalov, J.; Bowler, C.; Giovannoni, J. Manipulation of light signal transduction as a means of modifying fruit nutritional quality in tomato. Proc. Natl. Acad. Sci. USA 2004, 101, 9897-9902. [CrossRef] [PubMed]

27. Lee, J.M.; Joung, J.G.; McQuinn, R.; Chung, M.Y.; Fei, Z.; Tieman, D.; Klee, H.; Giovannoni, J. Combined transcriptome, genetic diversity and metabolite profiling in tomato fruit reveals that the ethylene response factor SIERF6 plays an important role in ripening and carotenoid accumulation. Plant J. 2012, 70, 191-204. [CrossRef] [PubMed]

28. Apel, W.; Bock, R. Enhancement of carotenoid biosynthesis in transplastomic tomatoes by induced lycopene-to-provitamin A conversion. Plant Physiol. 2009, 151, 59-66. [CrossRef] [PubMed]

29. Klee, H.J.; Giovannoni, J.J. Genetics and control of tomato fruit ripening and quality attributes. Annu. Rev. Genet. 2011, 45, 41-59. [CrossRef] [PubMed]

30. Chung, M.Y.; Vrebalov, J.; Alba, R.; Lee, J.; McQuinn, R.; Chung, J.-D.; Klein, P.; Giovannoni, J. A tomato (Solanum lycopersicum) APETALA2/ERF gene, SlAP2a, is a negative regulator of fruit ripening. Plant J. 2010, 64, 936-947. [CrossRef] [PubMed]

31. Galpaz, N.; Wang, Q.; Menda, N.; Zamir, D.; Hirschberg, J. Abscisic acid deficiency in the tomato mutant high-pigment 3 leading to increased plastid number and higher fruit lycopene content. Plant J. 2008, 53, 717-730. [CrossRef] [PubMed]

32. Menda, N.; Semel, Y.; Peled, D.; Eshed, Y.; Zamir, D. In silico screening of a saturated mutation library of tomato. Plant J. 2004, 38, 861-872. [CrossRef] [PubMed]

33. Saito, T.; Ariizumi, T.; Okabe, Y.; Asamizu, E.; Hiwasa-Tanase, K.; Fukuda, N.; Mizoguchi, T.; Yamazaki, Y.; Aoki, K.; Ezura, H. TOMATOMA: A Novel Tomato Mutant Database Distributing Micro-Tom Mutant Collections. Plant Cell Physiol. 2011, 52, 283-296. [CrossRef] [PubMed]

34. Saito, K.; Matsuda, F. Metabolomics for Functional Genomics, Systems Biology, and Biotechnology. Annu. Rev. Plant Biol. 2010, 61, 463-489. [CrossRef] [PubMed]

35. Benning, C. Genetic mutant screening by direct metabolite analysis. Anal. Biochem. 2004, 332, 1-9. [CrossRef] [PubMed]

36. Hyun, T.K.; Lee, S.; Rim, Y.; Kumar, R.; Han, X.; Lee, S.Y.; Lee, C.H.; Kim, J.Y. De-novo RNA Sequencing and Metabolite Profiling to Identify Genes Involved in Anthocyanin Biosynthesis in Korean Black Raspberry (Rubus coreanus Miquel). PLoS ONE 2014, 9, e88292. [CrossRef] [PubMed]

37. Fiehn, O. Metabolomics-The link between genotypes and phenotypes. Plant Mol. Biol. 2002, 48, $155-171$. [CrossRef] [PubMed]

38. Sérino, S.; Laurent, G.; Costagliola, G.; Gautier, H. HPLC Assay of Tomato Carotenoids: Validation of a Rapid Microextraction Technique. J. Agric. Food Chem. 2009, 57, 8753-8760. [CrossRef] [PubMed] 
39. Gupta, P.; Sreelakshmi, Y.; Sharma, R. A rapid and sensitive method for determination of carotenoids in plant tissues by high performance liquid chromatography. Plant Methods 2015, 11, 1-12. [CrossRef] [PubMed]

40. Fraser, P.D.; Pinto, M.E.S.; Holloway, D.E.; Bramley, P.M. Application of high-performance liquid chromatography with photodiode array detection to the metabolic profiling of plant isoprenoids. Plant J. 2000, 24, 551-558. [CrossRef] [PubMed]

41. Britton, G. General carotenoid methods. Methods Enzymol. 1985, 3, 113-149.

42. Pankratov, I.; McQuinn, R.; Schwartz, J.; Bar, E.; Fei, Z.; Lewinsohn, E.; Zamir, D.; Giovannoni, J.J.; Hirschberg, J. Fruit carotenoid-deficient mutants in tomato reveal a function of the plastidial isopentenyl diphosphate isomerase (IDI1) in carotenoid biosynthesis. Plant J. 2016, 88, 82-94. [CrossRef] [PubMed]

43. Giorio, G.; Yildirim, A.; Stigliani, A.L.; D'Ambrosio, C. Elevation of lutein content in tomato: A biochemical tug-of-war between lycopene cyclases. Metab. Eng. 2013, 20, 167-176. [CrossRef] [PubMed]

44. Krinsky, N.I.; Landrum, J.T.; Bone, R.A. Biologic mechanisms of the protective role of lutein and zeaxanthin in the eye. Annu. Rev. Nutr. 2003, 23, 171-201. [CrossRef] [PubMed]

45. Boileau, T.W.M.; Boileau, A.C.; John, W.; Erdman, J. Bioavailability of all-trans and cis-Isomers of Lycopene. Exp. Biol. Med. 2002, 227, 914-919. [CrossRef]

46. Burri, B.J.; Chapman, M.H.; Neidlinger, T.R.; Seo, J.S.; Ishida, B.K. Tangerine tomatoes increase total and tetra-cis-lycopene isomer concentrations more than red tomatoes in healthy adult humans. Int. J. Food Sci. Nutr. 2009, 60, 1-16. [CrossRef] [PubMed]

47. Cooperstone, J.L.; Ralston, R.A.; Riedl, K.M.; Haufe, T.C.; Schweiggert, R.M.; King, S.A.; Timmers, C.D.; Francis, D.M.; Lesinski, G.B.; Clinton, S.K.; et al. Enhanced bioavailability of lycopene when consumed as cis-isomers from tangerine compared to red tomato juice, a randomized, cross-over clinical trial. Mol. Nutr. Food Res. 2015, 59, 658-669. [CrossRef] [PubMed]

48. Murray, M.G.; Thompson, W.F. Rapid isolation of high molecular weight plant DNA. Nucleic Acids Res. 1980, 8, 4321-4326. [CrossRef] [PubMed]

Sample Availability: Samples of the tomatoes are available from the authors.

(C) 2017 by the authors. Licensee MDPI, Basel, Switzerland. This article is an open access article distributed under the terms and conditions of the Creative Commons Attribution (CC BY) license (http://creativecommons.org/licenses/by/4.0/). 